\title{
Prevalence of Hospital Acquired Infection and Antibiotic Trends in ICU in Southern India
}

\author{
Umar Rashid Khan, Rajeev Saxena, Ruby Dass, K. K. Lahiri. \\ S. V. Wankhede and Sana Rafiq Khuroo*
}

Kashibai Navle Medical College \& Hospital Narhe Pune, India

*Corresponding author

\section{Keywords \\ Hospital Acquired Infection, ICU}

\section{Article Info}

Accepted: 07 October 2020 Available Online: 10 November 2020

\section{A B S T R A C T}

300 patients were screened in ICUs of a tertiary care hospital in southern India to detect the rate of Hospital Acquired Infection (HAI) and antibiotic trends. Clinical samples received in the laboratory were processed as per CLSI (Clinical laboratory standard institute) guidelines. Patients were followed up to 72 hours post discharge. Markers of infection were noted and correlated with the findings in our laboratory. Kirby bauer antibiotic susceptibility test (ABST) was used for isolates with special reference to Extended Spectrum Beta lactamase (ESBL) production and Methicillin Resistant Staphylococcus aureus (MRSA). 10.7\% were detected to have HAI during their stay in the ICU. Males above 30 years showed higher prevalence of HAI. Respiratory tract infection (RTI) was the commonest nosocomial infection detected in 56.3\% of HAI cases, of which 19\% were VAP (Ventilator Associated Pneumonia). Urinary tract infection (UTI) was $25 \%$ being the second commonest, followed by Blood stream infection (BSI) $12.5 \%$. The most common organism isolated was Acinetobacter baumannii $33.4 \%$, followed by Klebsiella pneumoniae 19.4\%, \& Escherichia coli (E. coli) $16.6 \%$. $24.1 \%$ isolates were ESBL producers \& $66.6 \%$ were MRSA. Gram positive organisms showed $100 \%$ resistance to Penicillin G \& Erythromycin. However, Vancomycin, Linezolid, Tetracycline, Chloramphenicol, Teicoplanin \& Tigecycline were sensitive. 74\% of Gram-negative organisms were susceptible to Carbapenems \& $2 \%$ were resistant to Polymyxin B and Colistin. The only effective way to control HAIs is to continuous monitoring of prevalence of infective organisms with their ABST.

\section{Introduction}

Hospital acquired infection (HAI) is a key factor in determining clinical outcomes among patients admitted in intensive care units. Critically ill patients in intensive care unit (ICU) are 5-10 times more likely to acquire nosocomial infections than those in general wards. $^{[1,2]}$
Studies on nosocomial infections in ICUs found that respiratory tract infections, blood stream infections, urinary tract infections and soft tissue infections are the common nosocomial infections in ICUs. ${ }^{[3,4]}$ Samples of urine, blood, pus, sputum and endotracheal tube (ETT) secretions when evaluated had Gram negative isolates followed by Staphylococcus aureus, Coagulase negative Staphylococcus species and Enterococcus 
species. ${ }^{[6,7]}$ Among the Gram negative bacterial isolates there is a high prevalence of Acinetobacter among the ICU patients followed by Escherichia coli, Klebsiella pneumoniae, Pseudomonas species and Citrobacter species. ${ }^{[8,9]}$

These organisms isolated are highly resistant to antibiotics. Most of them are methicillin resistant Staphylococcus aureus, high level aminoglycoside producing Enterococci, vancomycin resistant Enterococci, $\beta$ Lactamase producing Escherichia coli and Klebsiella species \& carbapenem resistant members of family Enterobacteriaceae ${ }^{[10]}$.

The incidence and prevalence of multidrug resistant organisms are so high in the hospital settings that even effective drugs like fluoroquinolones, third generation cephalosporins, aminoglycosides etc. are fast losing their utility in covering hospital pathogens, thus restricting the choice of antimicrobials for treating serious infections has become the need of hour. Early recognition of bacteria and appropriate antimicrobial therapy are essential for controlling infection, preventing morbidity and mortality and improve the quality of life. Since limited data are available concerning hospital acquired infection and antibiotic susceptibility trends in our ICU therefore this study will help to investigate the cause of various nosocomial infections and isolate the various pathogens to species level and also determine the antibiotic susceptibility pattern of these pathogens. Knowing antibiotic sensitivity pattern of ICU is mandatory for making an antibiotic policy. ${ }^{[12]}$

\section{Materials and Methods}

A descriptive observational study carried out in the department of microbiology of a tertiary care hospital in Pune over a period of one year. A total of 300 patients were screened consecutively during the study period. Various clinical samples such as ETT, BAL, Blood, Pus, Urine, Sputum, and CSF were received in the microbiology laboratory and were processed as per CLSI guidelines. Patients were evaluated on daily basis and up to 72 hours post discharge from ICU. Markers of infection like total leukocyte count, temperature, blood pressure, respiratory rate, fraction of inspired oxygen $\left(\mathrm{FiO}_{2}\right)$, radiology, discharge from wound, burning micturation or any other clinical signs of infection was noted and correlated with the findings in our laboratory.

\section{Ethical considerations}

The study was reviewed and approved by institutional ethical committee.

\section{Specimen collection and transport}

The specimens collected were blood, urine, pus, respiratory samples like sputum, endotracheal secretion (ETT), and bronchoalveolar lavage (BAL), body fluids like cerebrospinal fluid (CSF), pleural fluid, peritoneal fluid, and synovial fluids. Pus samples from superficial wound were collected in swab transport system. Pus samples from deep wounds were aspirated and collected in sterile screw capped containers. ${ }^{[13]}$

\section{Processing}

The specimens were collected and processed asper CLSI (clinical laboratory standard institute) standards.

\section{Antibiotic susceptibility testing}

Antibiotic susceptibility tests were done on these isolates by Kirby Bauer disc diffusion method according to CLSI guidelines. 


\section{Detection of MRSA}

Method: Standard disc diffusion method

Procedure: Methicillin resistant staphylococcus (MRSA) was detected by standard disc diffusion method using cefoxitin $(30 \mu \mathrm{g})$. The discs were applied to the MHA plate swabbed with the test strain adjusted to 0.5 McFarland turbidity standards and incubated at $35^{\circ} \mathrm{C}$ for 24 hours.

Interpretation: The organisms were deemed methicillin resistant when zone of inhibition was $\leq 24 \mathrm{~mm}$ for cefoxitin discs. ${ }^{[14]}$

Quality control: Staphylococcus aureus ATCC 25923 was used as quality control strain.

\section{Detection of ESBL}

Method: Phenotypic disc confirmatory test (PCT).

Procedure: Extended spectrum $\beta$-lactamase (ESBL) was detected by phenotypic disc confirmatory test (PCT) using ceftazidime $(30 \mu \mathrm{g})$ and ceftazidime-clavulanic acid $(30 \mu \mathrm{g} / 10 \mu \mathrm{g})$ discs.

The discs were applied to the MHA plates swabbed with the test strain adjusted to 0.5 Mc Farland turbidity standards and incubated at $37^{\circ} \mathrm{C}$ for 24 hours.

Interpretation: A greater than or equal to five $(\geq 5 \mathrm{~mm})$ increase in the zone diameter for the ceftazidime/clavulanic acid combination disc versus the zone of the ceftazidime $(30 \mu \mathrm{g})$ when tested alone were considered as ESBL producing organism. ${ }^{[15]}$

Quality control: Escherichia coli ATCC 25922 strains were used as negative control.

\section{Results and Discussion}

From the 300 patients admitted 367 various clinical samples were received. Most of the samples were from respiratory tract $152(41.4 \%)$, followed by urine $127(34.6 \%)$, blood 63(17\%), pus 18(5\%) and body fluids $7(2 \%)$. Out of the total 367 samples received $235(64 \%)$ were from males and $132(36 \%)$ were from females. Only $40 \%$ of them showed significant growth while the rest did not show any growth or were insignificant. Out of the total 300 patients admitted 32 $(10.7 \%)$ were diagnosed to have developed nosocomial infection during their stay in the ICU (Table 1).

\section{Prevalence of HAI in ICU}

Most of the patients admitted in the ICU were from 30 to 60 years of age. Similar pattern was also seen in the 32 patients who developed HAI in the ICU. While age group of 30 years and less, showed the least HAI (Table 2).

Male predominance was seen in the study. A total of $20(62.5 \%)$ males and $12(37.5 \%)$ females got HAI during their stay in the ICU (Fig. 1).

\section{Distribution of nosocomial infections in ICU}

Among the 32 patients diagnosed with HAI, respiratory tract infection (RTI) was the most common infection $18(56.3 \%)$ in the ICU. It was further divided into ventilator associated pneumonia (VAP) 6(19\%) and non-ventilator associated pneumonia (NON-VAP) $12(37.3 \%)$. Urinary tract infection was the second common nosocomial infection acquired in the ICU seen in $8(25 \%)$ patients which was either catheter associated (CAUTI) $5(15.5 \%)$ or non-catheter associated UTI $3(9.5 \%)$. Blood stream infection due to 
central venous catheter (CRBSI) 3(9.5\%) or non-catheter associated blood stream infection (BSI) 1(3\%) was seen in 4 patients. Skin and soft tissue infection (SSTI) was noted in 2(6.2\%) patients (Fig. 2).

\section{Co-morbid conditions}

Out of the 32 patients acquiring nosocomial infection in the ICU 26 were having either one or more than one co-morbidity like diabetes (4), hypertension (6), Hypertension \& diabetes (4), obesity (2), autoimmune diseases (3), HIV (1), COPD (2), alcoholism (1), or cardiac pathology (3).

\section{Bacteriological profile of organisms causing nosocomial infections in the ICU}

Out of the 32 samples received in the laboratory for processing. 36 organisms were isolated in the various samples mentioned. Most of the isolates were gram negative $29(80.5 \%)$, followed by gram positive organisms 4(11.2\%), and fungal organisms constituted 3(8.3\%) isolates (Table 3).

From the total 36 pathogens isolated from various clinical samples 29 were found to be gram negative and Acinetobacter baumannii $12(33.4 \%)$ was the predominant pathogen isolated. Klebsiella pneumoniae 7(19.4\%), E.coli 6(16.6\%), Pseudomonas aeruginosa 2(5.5\%), Providencia rettgeri $1(2.8 \%)$ and Burkholderia cepacia 1(2.8\%) were the other pathogens isolated. 4 isolates were gram positive comprising of Staphylococcus aureus $3(8.4 \%)$ and Staphylococcus epidermidis $1(2.8 \%)$. Fungal pathogens isolated were 3 in number which comprised of Candida albicans 2(5.5\%), and Non candida albicans 1(2.8\%).

\section{Distribution of pathogens isolated in different nosocomial infections}

From the 36 pathogens found to be associated with nosocomial infection in our ICU 4 patients were having co-infection with more than 1 pathogen, 3 in respiratory samples and one in urine. Acinetobacter baumannii $11 / 21(52.4 \%)$ was the most common pathogen causing respiratory tract infections, followed by Klebsiella pneumoniae 4/21(19\%), Pseudomonas aeruginosa 2/21(9.5\%), Staph. aureus 2/21(9.5\%), E.coli $1 / 21(4.8 \%)$ and Burkholderia cepacia $1 / 21(4.8 \%)$.

From blood samples Acinetobacter baumannii, Staphylococcus epidermidis, Klebsiella pneumoniae, and E.coli, constituted $1 / 4(25 \%)$ each.

From urine samples Escherichia coli 4/9(44.5\%) was the most common organism causing urinary tract infection. Followed by Candida albicans 2/8(22.2\%), Providencia rettgeri and Non albicans candida from $1(11.1 \%)$ sample each.

From pus, only $2 / 2$ pathogens were found to be the causative agent of SSTI, Staphylococcus aureus $1 / 2(50 \%)$ and Klebsiella pneumoniae 1/2(50\%) (Table 4).

The overall prevalence of ESBL producing pathogens was found to be $24.1 \%$ out of the 29 Gram negative organisms isolated. E.coli being the most prevalent ESBL producer 2/6(33.3\%). Followed by Klebsiella pneumoniae $2 / 7(28.5 \%)$ and Acinetobacter baumannii $3 / 12(25 \%)$. Out of the 3 Staphylococcus aureus isolates methicillin resistance was seen in 2(66.6\%). One of them was isolated from ETT while the other was isolated from pus sample causing RTI \& SSTI respectively.

The various pathogens causing device induced infection and surgical site infection (Table 5). The rate of various device induced infections was calculated by the total number of infections per 1000 device days. 
VAP rate: No of VAP detected

$$
\frac{\text { Total ventilator days }}{\text { To of }} \times 1000
$$

The VAP rate in our hospital was; $6 / 631 \times 1000=9.5 / 1000$ ventilator days.

CRBSI rate: No of CRBSI detected

Total central line days $\times 1000$

CRBSI rate in our hospital was; $3 / 510 \times 1000$ $=5.88 / 1000$ central line days .

CAUTI rate: No of CAUTI detected

No of catheter days $\times 1000$

The rate of CAUTI in our hospital was; $5 / 1353 \times 1000=3.69 / 1000$ catheter days.

SSI rate: No of SSI detected No of post operative days $\times 100$

SSI rate in our hospital was; $2 / 57 \times 100=3.5$ $\%$

All the 300 patients taken up in the study were followed up throughout their stay in the hospital and the aim was to evaluated outcome of patients admitted in ICU. In all these 300 patients 32 had acquired nosocomial infection while the rest 268 did not. 7/32(21.8\%) patients with HAI died during their stay while $12 / 268(4.4 \%$ ) patients who did not have any HAI died while admitted. Male preponderance was seen in the outcome with $6(85.7 \%)$ males and $1(14.3 \%)$ female expiring with HAI. While $7(58.3 \%)$ males and 5(41.7\%) females expiring with Non-HAI. With respect to age, majority of the deaths with HAI occurred in patients above 60 years of $2 / 6(33.3 \%)$ followed by age group of $31-60$ years $5 / 21(23.8 \%)$.

Staphylococcus aureus showed $100 \%$ sensitivity to Gentamicin, Rifampicin, Cotrimoxazole, Clindamycin, Linezolid,
Vancomycin, Teicoplanin, Chloramphenicol, Tetracycline, and Tigecycline. Staphylococcus epidermidis showed $100 \%$ sensitivity to cefoxitin, gentamicin, rifampicin, cotrimoxazole, clindamycin, linezolid, vancomycin, teicoplanin, chloramphenicol, tetracycline and Tigecycline. MRSA showed 100\% susceptibility to Rifampicin, Linezolid, Vancomycin, Teicoplanin, Chloramphenicol, Tetracycline and Tigecycline. While it showed $50 \%$ susceptibility to Cotrimoxazole and Clindamycin (Graph 1).

We also classified them under two categories the Non-Fermenter GNBs (NF-GNB) and the Enterobacteriaceae GNBs (EB-GNB). The NF-GNB pathogens like Acinetobacter baumannii showed $100 \%$ susceptibility to Colistin, 91.66\% to Ampicillin + sulbactam while it showed $75 \%$ susceptibility to ampicillin. Pseudomonas aeruginosa was 100\% sensitive to Ampicillin, Ampicillin + sulbactam, Ceftazidime, Ciprofloxacin, Amikacin, Gentamicin, Piperacillin + tazobactam, Colistin, Imipenem, and Meropenem while Burkholderia cepacia was $100 \%$ susceptible to Ampicillin + sulbactam, Cefotaxime, Cefepime, Ceftazidime, Amikacin, Gentamicin, Tigecycline, Piperacillin + tazobactam, Imipenem, Meropenem, Colistin and Polymyxin-B. EBGNB like Klebsiella pneumoniae showed $100 \%$ susceptibility to Imipenem, Meropenem and Colistin, while it showed $71.4 \%$ sensitivity to Piperacillin + tazobactam. $E$. coli showed $100 \%$ susceptibility to Colistin and $83.3 \%$ to ampicillin. It showed $66.6 \%$ sensitivity towards Imipenem, Meropenem, and Nitrofurantoin. Providencia rettgeri showed $100 \%$ susceptibility to Amoxicillin, Co-amoxyclav, Ampicillin + sulbactam, Amikacin, Piperacillin + tazobactam, Cefepime, Imipenem, and Meropenem but was resistant to Colistin (Graph 2). 


\section{Prevalence of nosocomial infections in ICU}

With respect to prevalence of hospital acquired infection, in our study 32 patients developed nosocomial infection during their stay in the ICU with a rate of $10.7 \%$, which is in correlation with the study conducted by Sugata Dasgupta et al., ${ }^{[17]}$ who reported a prevalence of $12 \%$. Adriana et al., ${ }^{[16]}$, Vincent $\mathrm{JL}$ et $a l^{[18]}$ and Ashour et al., ${ }^{[19]}$ reported a higher prevalence of $20 \%, 20.6 \%$ and $24 \%$ respectively in their study The higher frequency in these studies could be due to broader criteria of selection of patients and poor infection control practices. Lower level of prevalence of infection in our study could be due to stringent infection control measures and a dedicated staff for ICU.

\section{Distribution of nosocomial infections in ICU}

From these 32 patients most of the infections were related to respiratory tract $18(56.3 \%)$. It was followed by urinary tract infection $8(25 \%)$. Blood stream infection comprised of $4(12.5 \%)$ and skin and soft tissue infection was $2(6.2 \%)$. Comparable results have been published by Ashour et al., ${ }^{[19]}$, Gunseren et al., ${ }^{[11]}$, Radji et $a l^{[20]}$, and Sugata Dasgupta et al., ${ }^{[17]}$.It is in contrast with the study conducted by Mythri et al., ${ }^{[21]}$ where the most common nosocomial infection was urinary tract infection followed by respiratory tract infection.

\section{Bacteriological profile of organisms causing Nosocomial Infection in ICU}

The predominance of Gram negative bacteria in our study is in concordance with the findings of some recent studies, (Zhanel et al.,$^{[22]}$, Patel et al., ${ }^{[5]}$, Al Jawady et $a ., l^{[1]}$ and Radji et al., ${ }^{[23]}$. The data is comparable to other studies as well. ${ }^{[1,22,24]}$ The overall decrease in gram positive cocci in comparison to gram negative bacilli may be due to the direction of empirical therapy towards the gram positive one and over the time the gram negative bacteria show resistance to this therapy. ${ }^{[1]}$

\section{Distribution of various pathogens in different nosocomial infections in ICU}

In the present study Acinetobacter baumannii $12(33.4 \%)$ was the most common organism causing respiratory tract infections, followed by Klebsiella pneumoniae 4(19.4\%), Staph.aureus 2(9.5\%) and Pseudomonas aeruginosa $2(9.5 \%)$.

Acinetobacter species are important causes of nosocomial infections and also cause community-acquired pneumonia and soft tissue infections in warm and humid climates. The National Nosocomial Infection Surveillance (NNIS) System, implicated Acinetobacter species in $7 \%$ of nosocomial pneumonias and $2 \%$ each of nosocomial blood stream, surgical site, and urinary tract infections in ICUs in the United States in 2003. ${ }^{[25]}$ Importantly, Acinetobacter was the only gram-negative bacillus that increased significantly in incidence as a cause of ventilator-associated pneumonia compared to other GNBs. In the SENTRY study from January 2009 to December 2011, Acinetobacter species were implicated in $7 \%$ of ICU infections in the United States and Europe. ${ }^{[26]}$ Infections with Acinetobacter are an independent risk factor for death and carry a crude mortality rate of $30 \%$ to $75 \%$, which is partly attributable to comorbidities of the hosts and incorrect choices of antimicrobial therapy. ${ }^{[26,27]}$ Regarding the latter factor, a study of A.baumannii isolates from 803 US health-care facilities noted that $60 \%$ were resistant to three classes of antibiotics and $34 \%$ to four classes. ${ }^{[28]}$ The findings are similar with the study conducted by Sharma SK et al. ${ }^{[29]}$ It is in contrast with Patel BV et 
al., ${ }^{[5]}$, Zhanel et al., ${ }^{[22]}$ and Al-Jawady et al., ${ }^{[1]}$

The Burkholderia cepacia complex, can cause nosocomial outbreaks of pneumonia and bacteremia in critically ill patients without cystic fibrosis, and are sometimes associated with contaminated medications and toiletries. ${ }^{[30]}$

Table.1 Showing prevalence of HAI in ICU

\begin{tabular}{|c|c|c|}
\hline HAI & No of Patients & Percentage \\
\hline Present & 32 & $10.7 \%$ \\
\hline Absent & 268 & $90.3 \%$ \\
\hline Total & 300 & $100 \%$ \\
\hline
\end{tabular}

Table.2 Age wise distribution of HAI in ICU

\begin{tabular}{|c|c|c|}
\hline Age & Patients with HAI & Percentage \\
\hline$\leq \mathbf{3 0}$ & 5 & $15.6 \%$ \\
\hline $\mathbf{3 1} \mathbf{- 6 0}$ & 21 & $65.6 \%$ \\
\hline $\mathbf{7 6 0}$ & 6 & $18.8 \%$ \\
\hline Total & 32 & $100.0 \%$ \\
\hline
\end{tabular}

Table.3 Showing organisms isolated from ICU patients

\begin{tabular}{|c|c|c|}
\hline \multicolumn{2}{|c|}{ Organisms Isolated } \\
\hline Microorganisms & No. of isolates & Percentage \\
\hline Gram negative isolates & & \\
\hline Acinetobacter baumannii & 12 & 33.4 \\
\hline Klebsiella pneumoniae & 7 & 19.4 \\
\hline Escherichia coli & 6 & 16.6 \\
\hline Pseudomonas aeruginosa & 2 & 5.5 \\
\hline Providencia rettgeri & 1 & 2.8 \\
\hline Burkholderia cepacia & 1 & 2.8 \\
\hline Subtotal & $\mathbf{2 9}$ & $\mathbf{8 0 . 5}$ \\
\hline Gram positive isolates & & \\
\hline Staphylococcus aureus & 3 & 8.4 \\
\hline Staphylococcus epidermidis & 1 & 2.8 \\
\hline Subtotal & $\mathbf{4}$ & \\
\hline Fungal isolates & & 5.5 \\
\hline Candida albicans & 2 & 2.8 \\
\hline Non albicans candida & 1 & $\mathbf{8 . 3}$ \\
\hline Subtotal & $\mathbf{3}$ & $\mathbf{1 0 0}$ \\
\hline Total Isolates & $\mathbf{3 6}$ \\
\hline
\end{tabular}


Table.4 Pathogens isolated in different nosocomial infection

\begin{tabular}{|c|c|c|c|c|c|}
\hline Organisms & RTI & BSI & UTI & SSTI & Total No \\
\hline Acinetobacter baumannii & 11 & 1 & 0 & 0 & 12 \\
\hline Klebsiella pneumoniae & 4 & 1 & 1 & 0 & 6 \\
\hline Escherichia coli & 1 & 1 & 4 & 0 & 2 \\
\hline Pseudomonas aeruginosa & 2 & 0 & 0 & 0 & 1 \\
\hline Burkholderia cepacia & 1 & 0 & 0 & 0 & 1 \\
\hline Providencia rettgeri & 0 & 0 & 1 & 1 & 3 \\
\hline Staph.aureus & 2 & 0 & 0 & 0 & 2 \\
\hline Staph.epidermidis & 0 & 1 & 0 & 0 & 1 \\
\hline Candida albicans & 0 & 0 & 2 & 0 & 36 \\
\hline Non albicans candida & 0 & 0 & 1 & 2 & \\
\hline Total organisms & $\mathbf{2 1}$ & $\mathbf{4}$ & $\mathbf{9}$ & & $\mathbf{3}$ \\
\hline
\end{tabular}

Table.5

\begin{tabular}{|c|c|c|c|c|}
\hline Pathogen & VAP & CRBSI & CAUTI & SSI \\
\hline Acinetobacter baumannii & 1 & - & - & - \\
\hline Acinetobacter baumannii $\boldsymbol{E S B L}$ & 2 & 1 & - & - \\
\hline Klebsiella pneumoniae & - & - & - & - \\
\hline Klebsiella pneumoniae ESBL & 1 & 1 & - & - \\
\hline E.coli & - & - & - & - \\
\hline E.coli ESBL & - & - & - & - \\
\hline Burkholderia cepacia & 1 & - & - & - \\
\hline Providencia rettgeri & - & - & - & - \\
\hline Staph.epidermidis & - & 1 & - & 1 \\
\hline MRSA & 1 & - & - & - \\
\hline Candida albicans & - & - & $\mathbf{2}$ & 2 \\
\hline Total & $\mathbf{6}$ & $\mathbf{3}$ & $\mathbf{5}$ & \\
\hline
\end{tabular}

Fig.1 Gender wise distribution of the patients having HAI

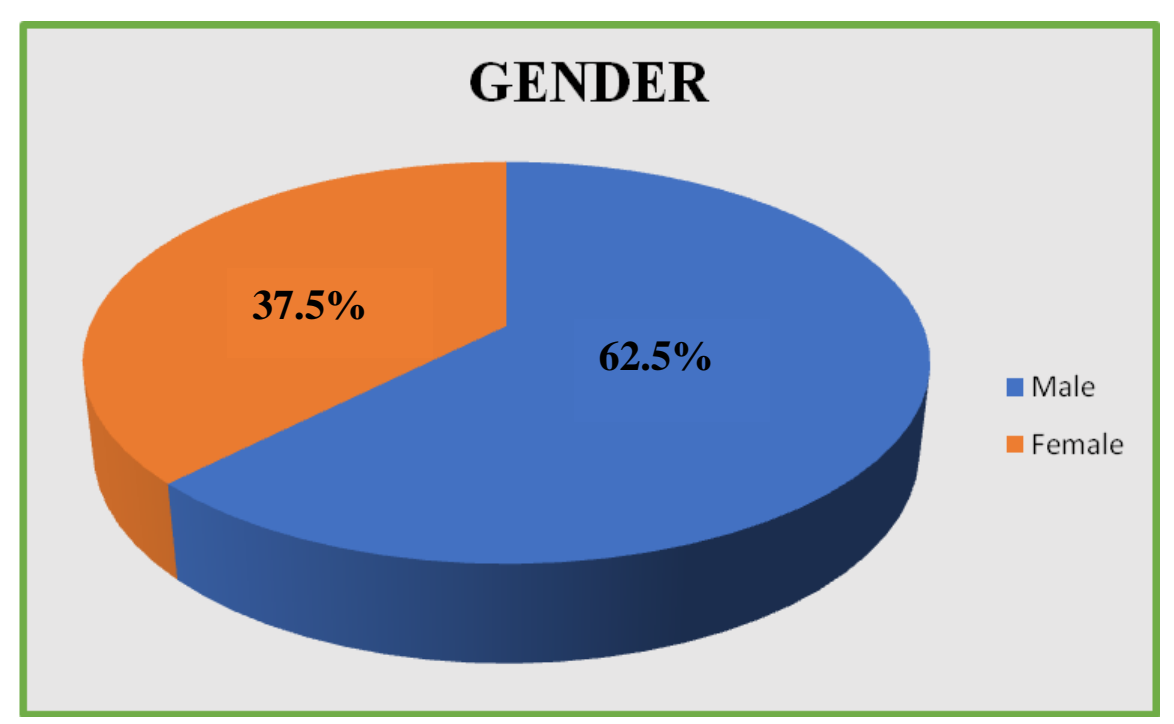


Fig.2 Distribution of nosocomial infections in ICU

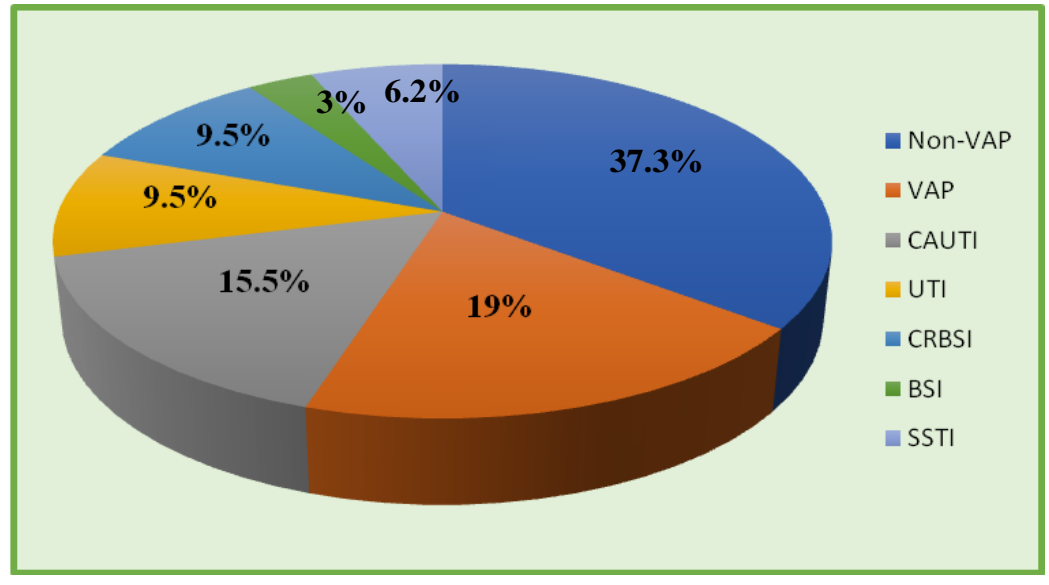

Graph.1 Antibiotic sensitivity pattern of Gram-positive organisms causing HAI in ICU

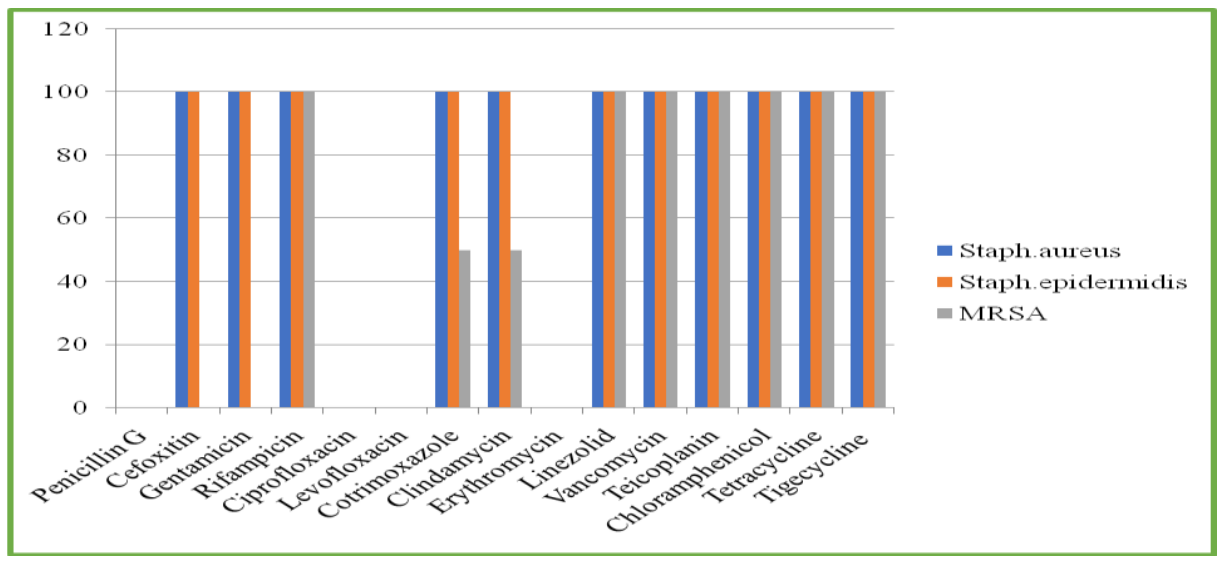

Graph.2 Antibiotic sensitivity pattern of Gram negative organisms causing HAI in ICU

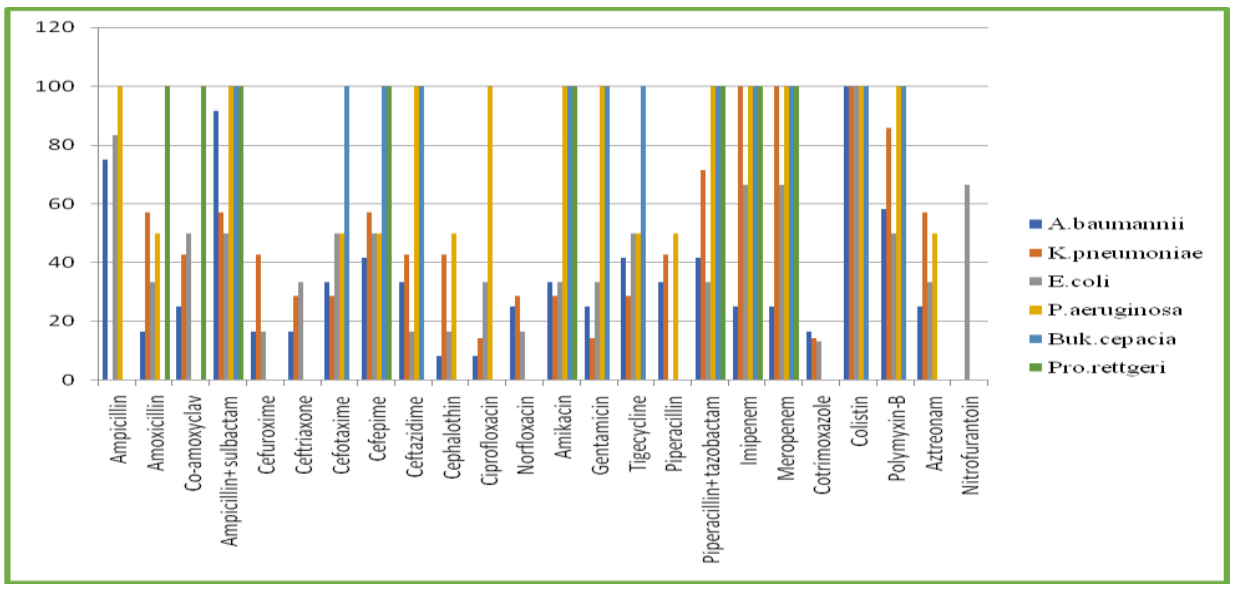


Prevalence of ESBL production and MRSA in the pathogens isolated

Overall, the total percentage of ESBL producers among gram negative bacteria like Acinetobacter baumannii, E.coli and Klebsiella pneumoniae was $24.1 \%$. The percentage of ESBL producer among Acinetobacter baumannii was $3 / 12(25 \%)$. In Klebsiella pneumoniae it was $2 / 7(28.5 \%)$ and in E.coli it was 2/6(33.3\%).

Our data correlates with Oberoi L et al., ${ }^{[31]}$ who reported a prevalence of $35.16 \%$ in ICU in Punjab. Other investigators from India reported different findings, $68.78 \%$ in New Delhi (Srujana Mohanty et al., 2005) ${ }^{[32]}, 53 \%$ in Mumbai (C Rodrigues et al., 2004) ${ }^{[33]}$, and 57.69\%-61.11 \% in Allahabad (Vipin Kumar et al., 2011) ${ }^{[34]}$, emphasizing that the prevalence of ESBL can vary greatly from one place to another and even over time. ${ }^{[35]}$ This contrast may be due to difference in selective antibiotic pressure because of local hospital antibiotic policy, and also infection control practices in hospitals. Studies show that the epidemiology of MRSA over different parts of India is not uniform. In the present study, we reported $66.6 \%$ MRSA among S.aureus isolates. Whereas, others have reported variable percentages, $54.9 \%$ in Anantapur (Habeeb Khadri et al., 2010) ${ }^{[36]}$, $68.44 \%$ in Varanasi (Hare Krishna Tiwari et al., 2008) $)^{[37]}$, another study done by Sangeeta Joshi et al., ${ }^{[38]}$ (INSAR group) in 2008 and 2009 in which 15 different tertiary care centre's all over India participated and reported an overall incidence of $43 \%$ in 2008 and $47 \%$ in 2009 of MRSA in the ICU.

Although it is extremely difficult to explain these conflicting data with regards to both time and place of study the variation is probably due to differential clonal expansion and drug pressure in community, and also differences in the infection control policies in
ICU. Patients in the ICU are more likely to be colonized or infected with an antimicrobial resistant pathogen than Non-ICU patients, therefore the rates of resistance are significantly higher in patients treated in the ICU than in Non-ICU patients. ${ }^{[39]}$

\section{Device induced nosocomial infection rates}

The VAP rate in our study was $9.5 / 1000$ ventilator days, CRBSI rate was 5.88/1000 central line days, CAUTI rate was 3.69/1000 catheter days, and SSI rate was $3.5 \%$. Which is corresponding to the study done by David J Weber et al., ${ }^{[40]}$, and Jimenez et al., ${ }^{41]}$

Our results were in slight dissimilarity with the results obtained by HG. Garcell et al., ${ }^{[42]}$. Who reported VAP rate of 20.5/1000, CRBSI rate of 2.3/1000, and CAUTI rate of 4.1/1000 days. The reason could be of a lesser patient number in their study as compared to ours. And prevalence of multi drug resistant bacteria in their ICU which can exponentially increase the infection rate in any health care facility.

\section{Antibiotic sensitivity pattern of organisms causing HAI}

Among the NF-GNB isolates, a high degree of resistance has been observed to almost all classes of antimicrobials tested such as cephalosporins, carbapenems, aminoglycosides and quinolones. This data is supported by various studies Mohammadimehr M et al., Maksum Radji et al., and Kaushal V Sheth et al., ${ }^{[43,23,12]}$ Acinetobacter spp was the most resistant organism in our study. 85\% of Acinetobacter spp were found to be resistant to be meropenem; whereas the cephalosporin resistance varied between 91.7\% (cephalothin) and 58.4\% (Cefepime). Even resistance to aminoglycosides and quinolones were also much higher $(66.7 \%$ to amikacin and $91.7 \%$ to ciprofloxacin). 
Kaushal V Sheth et al., ${ }^{[12]}$ had reported concordance resistance pattern for Acinetobacter spp to various class of antimicrobials. ${ }^{[12]}$ Tigecycline and cefepime was found to be more effective against Acinetobacter baumannii (41.6\%) compared to the other antimicrobials, hence it may be a promising agent for the treatment of Acinetobacter infections. Pseudomonas aeruginosa was also found to be resistant to several classes of antimicrobials tested, but the intensity of resistance was lower compared to Acinetobacter baumannii. Resistance of isolates of Pseudomonas to Ampicillin/sulbactam, Meropenem and amikacin was found to be minimal. While as Tigecycline and Pipercillin resistance was around $50 \%$. This is also in agreement to several other Indian studies published in the recent past. ${ }^{[43,23,12]}$

Among EB-GNB, we noted high degree of resistance to cephalosporins $(42.9 \%-83.4 \%)$ $\& \quad$ quinolones $(66.7 \%-85.7 \%) \quad$ and aminoglycosides (66.7\%-85.7\%). Resistance was lower on addition of beta lactamase inhibitor, $(0 \%-50 \%$ resistance against Amoxicillin/clavulanic acid). Significant resistance to carbapenams $(33.4 \%)$ was also seen. In general, E.coli followed by Klebsiella pneumoniae were found to be more resistant as compared to Providencia rettgeri. This data is supported by studies of Al Jawady et al., ${ }^{[1]}$, Mahin Jamshidi et al., Mohammadimehr et al., Ganguli et al., ${ }^{[44,43,45]}$

In the Gram positive group, all strains of S.aureus were found to be resistant against penicillin and ciprofloxacin (100\%). This finding is also supported by Maksum Radji et al., Kaushal V. Sheth et al., Ganguli et al., ${ }^{[23,12,45]}$ In our study, about $(50 \%)$ of Staphylococcus species were found to be Methicillin Resistant (MR). There are several studies which documented the incidence of MR between (30\%-50\%) among hospitalized patients. ${ }^{[46,20,12]}$ The increasing incidence of MR is alarming as no beta lactams drug would work in this situation and increase use of vancomycin opens the possibility of emergence of vancomycin resistance in S.aureus in near future. However, no vancomycin resistance has been reported in our study in concordance to other Indian studies.

The prevalence of MDR among gramnegative bacilli has significantly increased in recent times. ${ }^{[47,48,23]}$ Emergence of these organisms can lead to increased mortality, morbidity, economic burden and longer hospital stay. We made an attempt to calculate co-resistance among MDR gramnegative organisms. We found that $55.17 \%$ (16 out of 29) of the significant GNB isolates were MDR and are resistant to at least 3 or more classes of antimicrobials. Maximum MDR was reported from Acinetobacter baumannii (75\%), this was supported by study conducted by Aurora E et al., ${ }^{[4]}$, where it was found that $35 \%$ of GNB isolates were resistant to 4 antimicrobial groups, and 12\% were resistant to 5 antimicrobial groups. $[47,44,48,23]$

The findings in our study were found to be closer to the lower range of prevalence rates reported in the other studies referred above. This difference in findings is not necessarily related to better quality of care, since many other factors may be responsible including difference in the criteria for patient selection, the case mix, ICU type, length of stay, rate of device utilization and discharge criteria. ${ }^{[24,50]}$ The patients from a single institution can present with different risk of infection in the context of differing case mix, severity of illness and utilization rates of invasive devices. ${ }^{[51]}$

In the EPIC II study, ${ }^{[56,49]}$ the most frequently reported sites for ICU acquired infections 
were the lungs (64\%), abdominal (19\%), and blood stream (15\%). Data from the United States National Nosocomial infections surveillance (NNIS) system showed that the nosocomial pneumonia accounted for $31 \%$ of all nosocomial infections followed by urinary tract infections and blood stream infections. ${ }^{[51]}$ The site distribution of nosocomial infections in this study broadly conforms to the findings of earlier and larger studies mentioned above.

The precise pattern of causative organisms, whether bacterial or fungal, varies across countries and between ICUs according to patient case mix, site of infection, antibiotic protocols, infection control practice and local ecology and resistance patterns. ${ }^{[52]}$ Most studies report that more than half of the nosocomial infections occurring in the ICU are due to Gram-negative bacteria. ${ }^{[49,51]}$ In our study too, the most commonly isolated organisms were Non Fermenter Gramnegative bacteria especially Acinetobacter baumannii which was the single most pathogen isolated, followed by Enterobacteriaceae. The detection of Candida species in $9.3 \%$ of the isolates in the present study is also consistent to some extent with the studies of Pittet and Wenzel ${ }^{[53,55]}$ and Edgeworth et al., ${ }^{[54]}$ who have reported that fungal pathogens are also becoming increasingly common among patients with nosocomial infections.

\section{Recommendation}

A robust and effective hospital infection control policy, Antimicrobial Stewardship Programe (ASP) with frequent revisions of antimicrobial policy guidelines is mandatory and is the only way to control HAIs and AMR (Anti-Microbial Resistance).Interventions to control spread of resistant bacteria causing nosocomial infections include optimizing antibiotic selection and dosing strict adherence to infection control practices and rational use of antibiotic combinations. Antimicrobial sensitivity pattern in ICU are crucial and important for giving effective treatment and decreasing the spread of resistance.

\section{References}

1. Al-Jawady ZA, Al-Habib HM. Antibiograrn Profiles of Bacterial Isolates from Intensive Care Units in Mosul Teaching Hospitals. Raf. J. Sci 2012; 23:52-9.

2. Datta P, Rani, Chauhan R, Gombar S, Chander J. Health-care-associated Infections: Risk factors and epidemiology from an intensive care unit in Northern India. Indian J of Anaesthesia 2014; 58:30-5.

3. Kaul, S., KN. Brahmadathan, M. Jagannati, TD. Sudarsanam, K. Pitchamuthu, G. John, OC. Abraham et $a l$. , One year trends in the gram-negative bacterial antibiotic susceptibility patterns in a medical intensive care unit in South India. Indian J Med Microbiol 2007; 25:230-5.

4. Dwivedi M, Mishra A, SinghRK, AzimA, BaroniaAK, Prasad KN. Nosocomial cross-transmission of Pseudomonas aeruginosa between patients in a tertiary intensive care unit. Indian J Pathol and Microbiol 2009; 52: 509-13.

5. Patel BV, Patel PG, Raval PN, Patel MH, Patel PH, Vegad MM. Bacteriological profile and antibiogram of Gram negative organisms isolated from neurology intensive care unit with special reference to multidrug resistant organisms. National J Med Res 2012; 2: 335-8.

6. Robert AW. Nosocomial infection update. Emerging Infectious Diseases 1998; 4:416-20.

7. Kukukates E, Kocazeybek B. High resistance rate against 15 different 
antibiotics in aerobic Gram-negative bacteria isolates of Cardiology Intensive Care Unit patients. Indian J Med Microbiol 2002; 20: 208-10.

8. Sharma DK, Tiwari YK, Vyas N, Maheshwari RK. An investigation of the incidence of Nosocomial infections among the patients admitted in the intensive care unit of a tertiary care hospital in Rajasthan, India. Int $\mathbf{J}$ curt. Microbiol App Sci., 2013; 2: 428-35.

9. Richard A P, Saiman L. Nosocomial Infections in the Neonatal Intensive Care Unit. NeoReviews2003; 4: 81- 9.

10. Gangurde N, Mane M, Phatale S. Prevalence of Multidrug Resistant Enterococci in a Tertiary Care Hospital in India: A Growing Threat. Open $\mathrm{J}$ of Medical Microbiology, 2014; 4: 11-5.

11. Gunseren F, Mamikoglu L, OzturkS, Yucesoy M, Biberoklu K, Yulug N et al., A surveillance study of antimicrobial resistance of Gram- negative bacteria isolated from intensive care units in eight hospitals in Turkey. $\mathbf{J}$ Antimicrobial Chemotherapy 1999; 43: 373-8.

12. Sheth KV, Patel TK, Malek SS, Tripathi CB. Antibiotic Sensitivity Pattern of Bacterial Isolates from the Intensive Care Unit of a Tertiary Care Hospital in India. Tropical Journal of Pharmaceutical Research 2012; 11 991-9.

13. Mahon CR, Lehman DC, Man wellie G, Text book of Diagnostic Microbiology. $3^{\text {rd }}$ edition. New Delhi: Elsevier; 2007.

14. Comparison of Cefoxitin and Oxacillin Disk Diffusion Methods for Detection of mecA-Mediated Resistance in Staphylococcus aureus in a Large-Scale Study. Nicole M. Broekema, Tam T. Van, Timothy A. Monson, Steven A. Marshall and, David M. Warshauer. J. Clin. Microbiol. January 2009 vol. 47 no.1:217-219

15. Kumar MS, Lakshmi V, Rajagopalan R, Occurrence of Extended spectrum beta lactamases among Enterobacteriaceae species isolated at a tertiary care institute. Indian J Med Microbiol 2006: 24; 208-11

16. Oliveira Adriana Cristina de, Kovner Christine Tassone, Silva Rafael Souza da. Nosocomial Infection in an Intensive Care Unit in a Brazilian University Hospital. Rev. Latino-Am. Enfermagem. 2010. Apr [cited 2017 Oct 21]; 18(2): 233-39.

17. Sugata Dasgupta. Das S, Chavan NS, HazraA. Nosocomial infections in the intensive care unit: incidence, risk factors, outcome and associated pathogens in a public tertiary teaching hospital of Eastern India. Indian $\mathrm{J}$ Critical care medicine. 2015: 19: 14-20.

18. Vincent JL1, Bihari DJ, Suter PM, Bruining HA, White J, Nicolas-Chanoin MH, Wolff M, Spencer RC, Hemmer M. The Prevalence of Nosocomial Infection in Intensive Care Units in Europe Results of the European Prevalence of Infection in Intensive Care (EPIC) Study Author Affiliations. JAMA. 1995; 274(8): 639644.

19. Dr Majdi Ashour, MD. Khalil El-Nakhal. MD Published. Nosocomial infection in patients admitted to an intensive care unit at Al-Shifa Hospital in the Gaza Strip, occupied Palestinian territory: a retrospective assessment: October 2012. THE LANCET

20. Koneman E, Allen S, Janda W, Schrcckenberger P, Winn W. Colour atlas and textbook of diagnostic microbiology. 6th edition, Lippincott Kaven Publisher, Philadelphia; 1997:624-71.

21. Mythri H, Kashinath KR. Nosocomial infections in patients admitted in intensive care unit of a tertiary health center, India. Ann Med Health Sci Res 2014:4:738-41.

22. ZhaneI GG, DeCorbyM, Laing N, Weshnoweski B, Vashist R, Tailor F et al., Antimicrobial resistant pathogens in 
Intensive Care Units in Canada: Results of the Canadian National Intensive Care Unit (CAN-leU) study, 2005-2006. Antimicrob.Agents Chemother 2008; 52: 1430-7.

23. Rajdi M, Fauziah S, Aribinuko, Antibiotic sensitivity pattern of bacterial pathogens in the intensive care unit of Fatmawati hospital, Indonesia, Asian Paed J Trop Biomed 2011;1:39-42

24. Erbay, H., Yalcin, A.N., Serin, S. et al., Nosocomial infections in intensive care unit in a Turkish university hospital: a 2year survey. Intensive Care Med (2003) 29: 1482.

25. Sader HS, Farrell DJ, Flamm RK, Jones RN. Antimicrobial susceptibility of gramnegative organisms isolated from patients hospitalized in intensive care units in United States and European hospitals (2009-2011). Diagn Microbiol Infect Dis. 2014; 78(4): 443-448.

26. Gaynes R, Edwards JR. Overview of nosocomial infections caused by Gram negative bacilli. CID 2005; 41: 848-54.

27. Lee YT, Kuo SC, Yang SP, et al., Impact of appropriate antimicrobial therapy on mortality associated with Acinetobacter baumannii bacteremia: relation to severity of infection. Clin Infect Dis. 2012; 55(2): 209-215.

28. Kallen AJ, Hidron AI, Patel J, Srinivasan A. Multidrug resistance among gramnegative pathogens that caused healthcare-associated infections reported to the National Healthcare Safety Network, 2006-2008. Infect Control Hosp Epidemiol. 2010; 31(5): 528-531.

29. Sharma SK, Hadda V, Mathur P, Gulati V, Sahney C. Profile of microorganisms in intensive care unit of a level - 1 trauma centre: A retrospective study. Indian J Crit Care Med 2013; 17: 87-91.

30. Liao $\mathrm{CH}$, Chang HT, Lai CC, et al., Clinical characteristics and outcomes of patients with Burkholderia cepacia bacteremia in an intensive care unit. Diagn Microbiol Infect Dis. 2011; 70(2): 260-266. [PubMed]

31. Oberoi, L., Singh, N., Sharma, P., \& Aggarwal, A. (2013). ESBL, MBL and Ampc $\beta$ Lactamases Producing Superbugs - Havoc in the Intensive Care Units of Punjab India. Journal of Clinical and Diagnostic Research : JCDR, 7(1), 70-73. http://doi.org/10.7860/JCDR/2012/5016.2 673

32. Srujana Mohanty, Ritu Singhal, Seema Sood, Benu Dhawan, Bimal K Das and Arti Kapil. Comparative in vitro activity of beta-lactam / beta lactamase inhibitor combinations against gram negative bacteria. Indian J Med Res November 2005: 122: pp. 425-428.

33. C Rodrigues, $\mathrm{P}$ Joshi, SH Jani, M Alphonse, R Radhakrishnan, A Mehta. Detection of $\beta$-lactamases in nosocomial gram negative bacteria. Indian Journal of Medical Microbiology, 2004; 22 (4):247250.

34. Vipin Kumar, Rohit Kumar, Avantika Chandra and Pramila Gupta. Incidence of $\beta$-lactamase producing gram negative clinical isolates and their antibiotic susceptibility pattern. A case study in Allahabad. International Journal of Research in Pure and Applied Microbiology. 2011:1(3): 36-39

35. Michael A. Pfaller and John Segreti. Overview of the Epidemiological Profile and Laboratory Detection of Extended Spectrum $\quad \beta$-Lactamases. $\quad$ Clinical Infectious Diseases 2006' 42 (Suppl. 4):S153-63.

36. Habeeb Khadri and Mohammad Alzohairy. Prevalence and antibiotic susceptibility pattern of methicillinresistant and coagulase negative staphylococci in a tertiary care hospital in India. International Journal of Medicine and Medical Sciences. April 2010, vol 2(4): p 116-120 
37. Hare Krishna Tiwari, Darshan Sapkota, Malaya Ranjan Sen. High prevalence of multidrug resistant MRSA in a tertiary care hospital of northern India. Infection and Drug Resistance, 2008: 1: 57-61.

38. Sangeeta Joshi. et al., Methicillin resistant Staphylococcus aureus (MRSA) in India: Prevalence \& susceptibility pattern. Indian Network for Surveillance of Antimicrobial Resistance (INSAR) group, India,. Indian J Med Res. 2013 Feb; 137(2): 363-369.

39. Aysen Bayram and IclalBalci. Patterns of Antimicrobial resistance in a surgical intensive care unit of a university hospital in turkey. BMC infectious diseases. 2006; 6:155.

40. David J. Weber, MD, MPH. Nosocomial Infections in the ICU The Growing Importance of Antibiotic-Resistant Pathogens; MPH CHEST: 1999: 115: 34S-41S. http://journal.publications. chestnet.org/ by a University of North Carolina User on 09/02/2015

41. P. Cornejo-Juárez, D. Vilar-Compte C. Pérez-Jiménez, S. SandovalHernández. The impact of hospital-acquired infections with multidrug-resistant bacteria in an oncology intensive care unit. International Journal of Infectious DiseasesVolume 31, February 2015, Pages 31-34.

42. H.Guanche-Garcell, O. Requejo-Pino, V.D. Rosenthal, C. Morales-Pérez, Delgado-González, D. FernándezGonzález. Device-associated infection rates in adult intensive care units of Cuban university hospitals: International Nosocomial Infection Control Consortium (INICC) findings International

43. Chawla K, Vishwanath S, Munim FC. Nonfermenting gram-negative bacilli other than Pseudomonas aeruginosa and Acinetobacter spp. causing respiratory tract infections in a tertiary care center. $\mathbf{J}$
Glob Infect Dis. 2013; 5(4): 144-48.

44. Pop-Vicas, Aurora \& L Mitchell, Susan \& Kandel, Ruth \& Schreiber, Robert \& M C D'Agata, Erika. (2008). MultidrugResistant Gram-Negative Bacteria in a Long-Term Care Facility: Prevalence and Risk Factors. Journal of the American Geriatrics Society. 56. 1276-80.

45. Mohammadi-mehr M, Feizabadi MM. Antimicrobial resistance pattern of Gramnegative bacilli isolated from patients at ICUs of Army hospitals in Iran. Iran J Microbiol. 2011; 3(1): 26-30.

46. Loomba PS, Taneja J, Mishra B. Methicillin and vancomycin resistant $S$. aureus in hospitalized patients. Journal of Global Infectious Diseases. 2010; 2(3): 275.

47. Masgala A, Kostaki K, Ioannnidis I. Multi Drug Resistant Gram Negative Pathogens in Long Term Care Facilities: A Steadily Arising Problem. J Infect Dis Diagn. 2015; 1: 101.

48. Ganguly NK, Arora NK, Chandy SJ, Fairoze MN, Gill JS, Gupta U, et al., Rationalizing antibiotic use to limit antibiotic resistance in India+ The Indian journal of medical research. 2011;134(3):281

49. Vincent JL, Rello J, Marshall J, Siva E, Anzueto A, Martin CD, et al., The extended prevalence of infection in the ICU study: EPIC II. JAMA. 2009; 302: 2323-9.

50. Richards MJ, Edwards JR, Culver DH, Gaynes RP. Nosocomial infections in medical infections surveillance system. Crit Care Med. 1999; 27: 887-92.

51. Richards MJ, Edwards JR, Culver DH, Gaynes RP. Nosocomial infections in combined medical-surgical intensive care units in the United States. Infect Control Hosp Epidemiol. 2000; 21: 510-5.

52. Vincent JL. Nosocomial infections in adult intensive-care units. Lancet. 2003; 361: 2068-77. 
53. Pittet D, Wenzel RP. Nosocomial bloodstream infections. Secular trends in rates, mortality, and contribution to total hospital deaths. Arch Intern Med. 1995; 155: 1177-84.

54. Edgeworth JD, Treacher DF, Eykyn SJ. A 25-year study of nosocomial bacteremia in an adult intensive care unit. Crit Care Med. 1999; 27: 1421-8.

55. Borna Mehrad, MBBS, Nina M. Clark, MD, George G. Zhanel, PhD, and Joseph P. Lynch, III, MD, FCCP. Antimicrobial
Resistance in Hospital-Acquired GramNegative Bacterial Infections. Chest. 2015 May; 147(5): 1413-1421.

56. Falagas ME, Kasiakou SK, Rafailidis PI, Zouglakis G, Morfou P. Comparison of mortality of patients with Acinetobacter baumannii bacteraemia receiving appropriate and inappropriate empirical therapy. J Antimicrob Chemother. 2006; 57(6): 1251-1254.

\section{How to cite this article:}

Umar Rashid Khan, Rajeev Saxena, Ruby Dass, K. K. Lahiri, S. V. Wankhede and Sana Rafiq Khuroo. 2020. Prevalence of Hospital Acquired Infection and Antibiotic Trends in ICU in Southern India. Int.J.Curr.Microbiol.App.Sci. 9(11): 723-738.

doi: https://doi.org/10.20546/ijcmas.2020.911.087 